\title{
Collaborative Online Examinations: Impacts on Interaction, Learning, and Student Satisfaction
}

\author{
Jia Shen, Starr Roxanne Hiltz, and Michael Bieber
}

\begin{abstract}
This paper presents the results of a field experiment on online examinations facilitated by collaboration support systems. In particular, it examines collaborative learning and virtual teams through online examinations as an assessment procedure, compared to traditional examinations. Assessment is increasingly regarded as an important part of the learning process. Applying constructivism and collaborative-learning theories, the collaborative examination process features students' active participation in various phases of the exam process through small group activities online. A $1 \times 3$ field experiment evaluated the collaborative online exam compared with the traditional in-class exam, and the participatory exam, where students participated in the online exam processes without groups. Data analysis using results from 485 students indicates that collaborative examinations significantly enhance interactions and the sense of an online learning community and result in significantly higher levels of perceived learning.
\end{abstract}

Index Terms-Asynchronous learning networks (ALNs), collaborative learning, collaborative work, peer assessment.

\section{INTRODUCTION}

A S COMPUTER networks and virtual teams proliferate, learning and knowledge sharing in the online environment become increasingly important. Yet, while collaborative learning in virtual classrooms [1] and asynchronous learning networks (ALNs) (see http://www.ALNResearch.org) have become widespread, traditional exams still dominate. Instructors control the exam process by designing questions and grading and administering exams; distance-learning students often have to travel to exam centers or take proctored exams.

Students should not only be evaluated but learn through assessment. With the total-quality movement and its adoption to education [2], [3], assessment has evolved from providing an accounting of students' learning to being increasingly regarded as an important part of the learning process [4]. The

Manuscript received October 1, 2005; revised April 21, 2006 and July 11, 2006. This work was supported in part by the Alfred P. Sloan Foundation, the United Parcel Service Foundation, the New Jersey Commission on Science and Technology under a grant to the New Jersey Center for Pervasive Information Technology, the National Science Foundation under Grants IIS0135531, DUE-0226075, DUE-0434998, and DUE-0434581, and the Institute for Museum and Library Services under Grant LG-02-04-0002-04. This paper was recommended by Guest Editor G. Cabri.

J. Shen is with the School of Management, New York Institute of Technology, New York, NY 10023-7692 USA (e-mail: jshen@ nyit.edu).

S. R. Hiltz and M. Bieber are with the Department of Information Systems, New Jersey Institute of Technology, Newark, NJ 07102-1982 USA (e-mail: hiltz@njit.edu; bieber@njit.edu).

Color versions of Figs. 2-4 are available online at http://ieeexplore.ieee.org.

Digital Object Identifier 10.1109/TSMCA.2006.883180 traditional instructor-controlled exam reflects the objectivist learning model [5], which regards learning as the uncritical transfer of objective knowledge from instructor to students. New assessment approaches based on constructivism theory [6], [7] propose that learners actually construct knowledge. For example, learner-centered assessment [8] and classroom assessment [9] shift the attention from instructors and teaching to students and learning through assessment. Actively engaging students in the entire exam process as online collaborative groups increases perceived learning and the sense of community.

Collaborative learning is a learner-centered and teamoriented approach that is based on constructivism and social learning theories [10] and assumes that learning emerges as learners interact with each other. Studies have shown the superiority of collaborative learning in both face-to-face settings and ALNs using group support systems (GSSs) [11]-[13] and in knowledge management in distributed teams (e.g., [14]).

Despite the collaborative-learning paradigm that dominates ALNs, only a few studies have been conducted to incorporate student active participation and collaboration into assessment processes online. With the use of GSSs, student participation and collaboration have been integrated into specific phases of the collaborative assessment, such as collaborative development of the grading scheme [15], question composition [16], collaborative question answering [17], and peer and self-grading [18]-[20]. One study that features student active participation in various phases of the exam was conducted at an American university [21]-[24]. The online exam was adopted in a graduate-level course for five semesters, where students designed essay-type exam questions, answered questions designed by peers, and graded answers to the questions they authored. The exams were conducted over a 3-4-week period using asynchronous conferencing systems. Student surveys revealed overall favorable attitudes toward the online exam process, including learning effects and high student satisfaction.

While initial studies revealed positive results through the students' active participation in the online exam process, the students' involvement in the exam was individual (termed "participatory exam" in this paper). To further incorporate constructivism and collaborative-learning theories, a "collaborative exam," which features students' participation in various phases of the exam process through small group activities online, was designed. Will small group online exam activities further enhance student interaction, learning, and satisfaction? The remainder of this paper answers this question by presenting the research model, study design, and experiment results. 


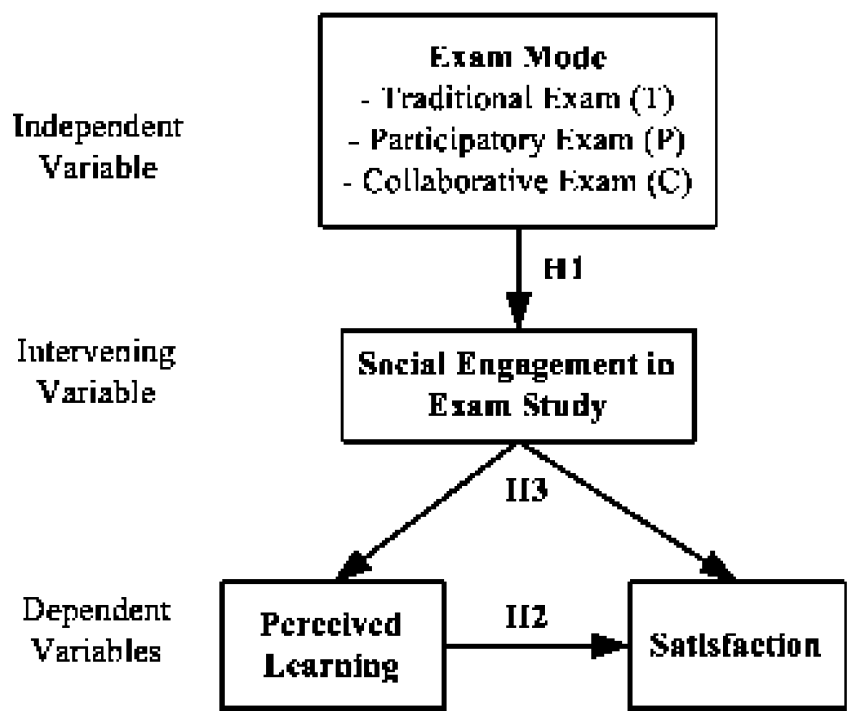

Fig. 1. Research framework.

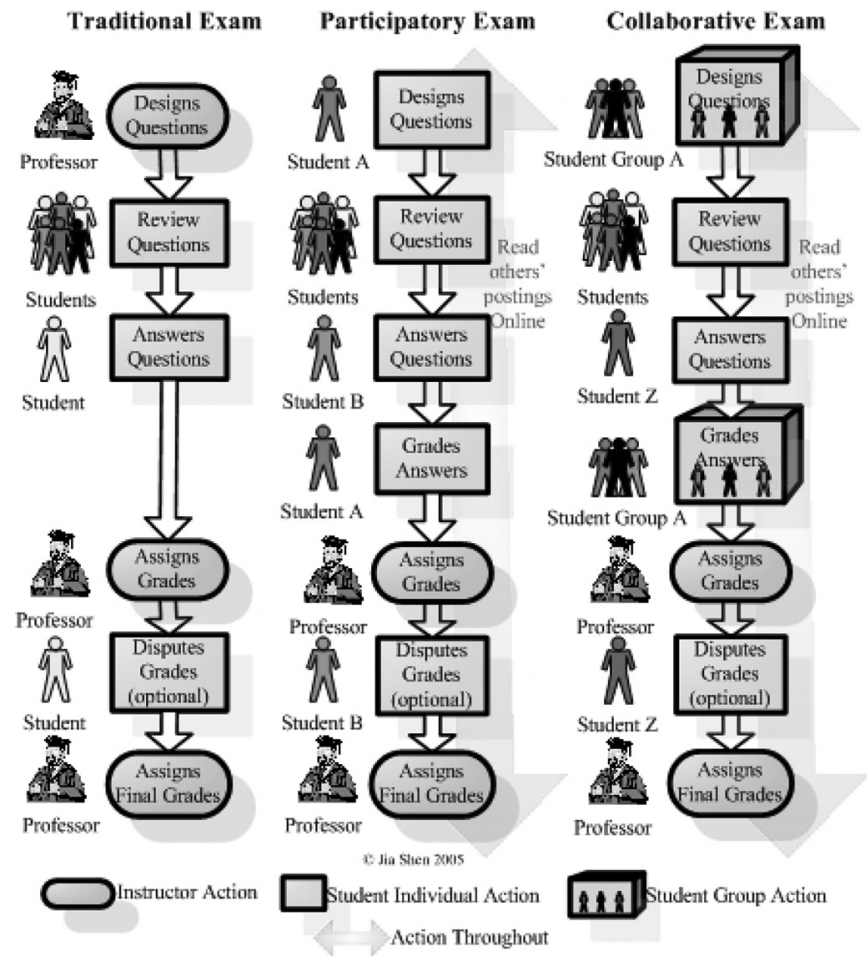

Fig. 2. Comparison of the three exam modes.

\section{RESEARCH FRAMEWORK AND HyPOTHESES}

This paper adopts a research framework based on the Online Interaction Learning Model developed by Hiltz, BenbunanFich, and Harasim [25]. Fig. 1 shows the research framework, which is a three-tier input-process-output model.

\section{A. Exam Mode}

The independent variable consists of three exam modes, namely: 1) the traditional exam; 2) the participatory exam; and 3 ) the collaborative exam. Fig. 2 compares and contrasts the three exam processes as they were conducted in this experiment.

The participatory exam and the collaborative exam both conduct exams online. Their differences lie in question design and grading. While students in the participatory exam perform these steps individually, students in the collaborative exam first participate individually (i.e., individually design questions and grades). Then, the group (three to five students) as a whole discusses, improves, and reaches a consensus on the questions and grades. Typically, essay-type questions are designed and answered by students.

After posting and before answering the questions, students in the online exams are given a couple of days to review all the questions posted online. During the review phase, the instructor reviews and revises the questions to ensure the quality of all the questions and then assigns questions to students. Throughout the online exam process, students in the online exams can read others' postings online. To make the three exam modes as comparable as possible, students in the traditional exam are also given a few days to review sample questions posted by the instructor online.

\section{B. Social Engagement, Perceived Learning, and Satisfaction}

Previous studies indicate that the extent of students' perceptions of their experiences in ALNs as actively involving, socially rich, and collaborative mediates the learning outcomes. Based on previous studies, this paper uses students' adoption of "social engagement" as the mediating variable, which is defined as the extent of the students' active involvement in learning from other students through the exam studying process, and the sense of forming a learning community through the exam process. The high adoption of social engagement in the exam studying process is reflected in a number of strategies a student uses when studying, such as getting to know other students better through the exam process and acknowledging learning from others. The dependent variables are students' "perceived learning" and "satisfaction." Perceived-learning measures based on Bloom's taxonomy [26] range from lower levels such as understanding materials to higher levels such as solving problems, comparing and discriminating ideas, and making predictions.

\section{Hypotheses}

Based on collaborative-learning theories and previous studies on online examinations [21]-[23], it was hypothesized that students in the collaborative exam would adopt higher levels of social engagement in the exam studying process and would have higher perceptions of the exam (H1), that students' perceived learning would be positively related to satisfaction (H2), and that social engagement would mediate students' perceptions of the exams (H3). The hypotheses (with corresponding numbers on the research model) are hereby presented.

H1.1 Students taking the collaborative examination will have higher social engagement in the exam studying process than students taking the traditional exam (H1.1.1) or the participatory exam (H1.1.2). 
TABLE I

THE $1 \times 3$ FIELd EXPERIMENT AND NuMbER OF SUbJECTS

\begin{tabular}{|l|c|c|c|c|}
\cline { 2 - 5 } \multicolumn{1}{c|}{} & \multicolumn{3}{c|}{ Exam Mode } & Total \\
\cline { 2 - 5 } \multicolumn{1}{c|}{} & $\begin{array}{c}\text { Tradi- } \\
\text { tional }\end{array}$ & $\begin{array}{c}\text { Partici- } \\
\text { patory }\end{array}$ & $\begin{array}{c}\text { Collabo- } \\
\text { rative }\end{array}$ & \\
\hline No. of students & 235 & 152 & 199 & 586 \\
\hline $\begin{array}{l}\text { No. of students } \\
\text { answering the } \\
\text { surveys }\end{array}$ & 173 & 137 & 175 & 485 \\
\hline Return Rate & $73.6 \%$ & $90.1 \%$ & $87.9 \%$ & $82.8 \%$ \\
\hline
\end{tabular}

H1.2 Students taking the collaborative examination will have higher perception of learning than students taking the traditional exam (H1.2.1) or the participatory exam (H1.2.2).

H1.3 Students taking the collaborative examination will have higher satisfaction with the exam than students taking the traditional exam (H1.3.1) or the participatory exam (H1.3.2).

H2 Students' perceived learning with the exam will be positively related to students' satisfaction.

H3.1 The correlation between students' level of social engagement in the exam studying process and students' perceived learning will be higher in the collaborative exam than the traditional exam.

H3.2 The correlation between students' level of social engagement in the exam studying process and students' satisfaction with the exam will be higher in the collaborative exam than that in the traditional exam.

\section{RESEARCh DESIGN}

\section{A. Subjects}

To investigate the research questions, a $1 \times 3$ field experiment was designed and conducted in the spring, summer, and fall semesters of 2004 at an American university. A total of 22 course sections at the undergraduate and graduate levels participated in the experiment. Ideally, students from each course section would be randomly assigned to each of the exam modes. Given that the experiments were conducted in real field settings (i.e., real classes), total randomization in subject assignment was not feasible. The students' reaction to different exams in the same section and the instructors' workload were major concerns. Considering these issues, entire sections were assigned to one exam mode, and a balancing technique was used to assign sections with similar characteristics to different exam modes in order to counterbalance any preexisting differences among students. In addition, data on the subjects' characteristics and learning predispositions were collected using preexam surveys, and the results were analyzed to examine any significant preexisting differences among students in different exam modes.

Table I shows the number of subjects in each condition and the high response ratio. Extra credit toward the exam grade provided incentive to complete the surveys.

\section{B. Procedures}

Detailed exam instructions including question design and answer grading criteria were provided to the students before the exam. For this paper, the entire process took about 2.5 weeks online using WebBoard and WebCT, and the process was anonymous using pen names. Students in the traditional exam condition took the exam in class or through proctors in remote sites in distance-learning courses. The instructor provided the questions and graded the students' answers, and the students answered the questions. With the instructor's permission, course notes, books, or other references were allowed in the traditional exam. Grading criteria and guidelines that are equivalent to those of the collaborative exam were provided to the students before the exam. Questions of similar types (e.g., essay) were asked in matching course sections in different exam modes whenever possible.

Students in all three conditions filled out a preexam survey regarding their learning predispositions to measure the preexisting differences before the exam, as previously discussed. Shortly following the exam, students were asked to complete a postexam survey. The postexam questionnaire has many of the same questions for the three conditions to allow comparison. The questionnaires adapted items that have been validated [27], [28] and taken from previous studies on the collaborative exam [22], [23] with revisions and additions. The questions used are shown in the results section of this paper.

\section{Collaboration Support Systems Used}

WebBoard and WebCT were the asynchronous conferencing systems used to facilitate the three exams for this paper. Both systems have a threaded-discussion-forum component and are similar in terms of the interface and functionalities. The online exams were conducted mainly using the discussion-forum component on these two systems.

To best facilitate the exam processes, three types of exam conferences with different configurations and purposes were created. First, an exam announcements conference was created as a public conference for the instructor to post exam announcements, instructions, and in the case of the traditional exam, sample questions for students to review. The exam announcements conference was created in all three exam modes. Second, an online exam main conference was created as a public conference for students in the two online exam modes to post exam questions, answers, and grades. The online exam main conference was configured as anonymous to allow students to post messages anonymously using the question IDs they were assigned with. Third, an online exam private group conference was created as the private conference for each exam group in the collaborative exam. Here, group members discussed questions and grading during the question design phase and grading phase before posting their results in the online exam main conference. As an example, Fig. 3 shows a screenshot of the conferences on WebCT for the online collaborative exam.

Students in the online exams were instructed to post questions anonymously using the question IDs assigned to them as the "title" of their message in the online exam main conference. Answers and grades were to be posted as replies to the 


\begin{tabular}{|c|c|c|c|c|c|}
\hline \multicolumn{6}{|c|}{ Discussions } \\
\hline \multicolumn{2}{|c|}{ Compose message } & Topic settings & & & \\
\hline \multicolumn{6}{|c|}{ Click on a topic name to see its messages. } \\
\hline$\square$ & Topic & Unread & Total & Private & Anonymous \\
\hline$\square$ & Instructor Announcements & 0 & 37 & $\square$ & $\square$ \\
\hline$\square$ & Midterm Exam Announcements & 0 & 14 & $\square$ & $\square$ \\
\hline$\square$ & Midterm Exam Conference & 0 & 186 & $\square$ & $\nabla$ \\
\hline$\square$ & G1 & 0 & 69 & $\square$ & $\square$ \\
\hline$\square$ & G2 & 0 & 162 & $\square$ & $\square$ \\
\hline$\square$ & G3 & 0 & 89 & $\square$ & $\square$ \\
\hline
\end{tabular}

Fig. 3. Example of WebCT conferences in the collaborative exam. Note that the Midterm Exam Announcements is a public conference, the Midterm Exam Conference is a public and anonymous conference, and G1-G3 are private conferences for group discussions.

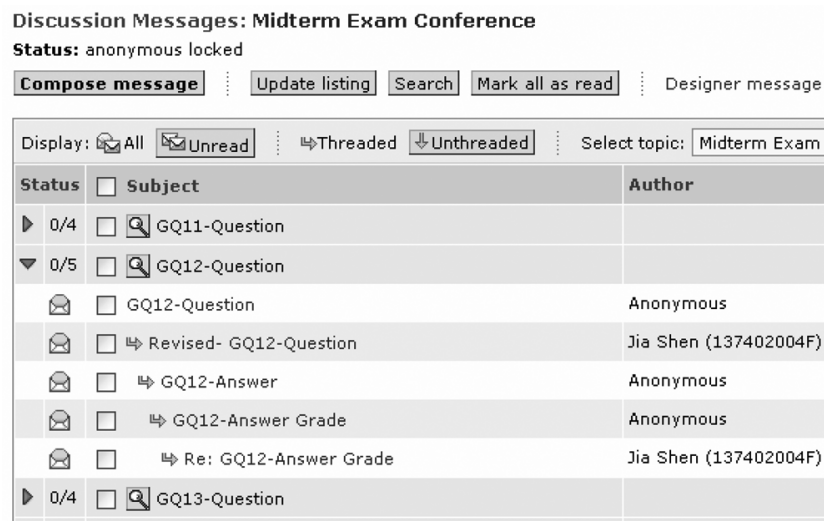

Fig. 4. Example of messages on WebCT in the collaborative exam. As shown, each question is a new thread of discussion. In addition, messages are posted anonymously except for the professor's (Prof. J. Shen in this example).

corresponding questions and answers. Similarly, the instructor was asked to post revised questions and answer grades as replies to the corresponding questions and answers. In the end, each question and the corresponding answer, student grade, instructor grade, dispute, and dispute resolution should appear as one thread. Fig. 4 shows an example of the online exam conference at the end of the collaborative exam process on WebCT. The threaded message structure at the end of the exam includes a message for each of the following: question, revised question (optional), answer, answer grading, final answer grading, dispute (optional), and resolution (optional).

While the focus of this paper is on comparing the three exam modes, it is observed that the use of computer collaboration systems not only streamlined the exam process but also enhanced students' learning. For example, the main exam conferences were set up to allow anonymous postings using question IDs. By posting the answer, grading, and grading dispute as replies to the original question message, each question has its own organized thread of discussion that is automatically displayed at the end of the exam process. Students can also read each other's postings throughout the exam process. As many students mentioned in the postexam interviews, this allowed them to learn from each other and to further their understanding of the course materials. In addition, the private conferences used in the collaborative online exam allowed group members to share ideas, reflect on others' ideas, and collaborate whenever and wherever they need to. These observations are consistent with previous studies on computer-mediated collaborative learning [11], [13], [29], [30], which suggest that collaborative systems increase student involvement with the course materials and each other, promote problem solving and critical thinking skills, encourage higher levels of critical thinking, and reduce rote memorization.

\section{FINDINGS}

The raw data were analyzed using the Statistical Package for the Social Sciences (SPSS). This section first presents the factor analysis and normalization test results, followed by item-level response analysis, and finally, hypothesis testing outcomes.

\section{A. Factor Analysis and Reliability of Scales}

Through principle component factor analysis with promax rotation, the following factors were extracted from the postexam survey results, which correspond to the constructs in the research model:

- Social engagement: 4 items, Cronbach's $\alpha=0.80$;

- Perceived learning: 12 items, Cronbach's $\alpha=0.93$;

- Student satisfaction: 4 items, Cronbach's $\alpha=0.81$.

As shown, the reliability analysis of the factors suggests that the factors are highly reliable, with values of Cronbach's $\alpha$ all above the 0.8 level. The mean scores were calculated for all the factors, and the data were tested for normal distribution. Social engagement and student satisfaction were normally distributed. While perceived learning was not normally distributed initially, data transformation was conducted by squaring the mean score (i.e., mean score $\times$ mean score), which successfully normalized the perceived-learning variable. The untransformed perceivedlearning score is used in univariate descriptive analysis (Section IV-B), and the transformed mean score is used in hypothesis testing (Section IV-C).

Before presenting the results from the postexam survey, it is necessary to point out that analysis using the preexam survey data shows that there is no significant difference among the students in the three exam modes before the exam, in terms of their learning predispositions.

\section{B. Univariate Analysis}

This section presents key descriptive results from the postexam survey on the individual-question-item level.

Social Engagement: Table II provides the results of the four items measuring the social engagement construct. In all four items, students in the collaborative online exam had the noticeably highest level of social engagement, including getting to know other students through the exam process $(\mathrm{T}=3.45$, $\mathrm{P}=2.98$, and $\mathrm{C}=4.49$ ), perceiving the exam as a group process $(\mathrm{T}=2.73, \mathrm{P}=2.46$, and $\mathrm{C}=4.17)$, forming a learning community through the exam studying process $(\mathrm{T}=3.57$, $\mathrm{P}=3.84$, and $\mathrm{C}=4.51$ ), and enhancing understanding of course materials by interacting with other students $(\mathrm{T}=3.80$, $\mathrm{P}=3.81$, and $\mathrm{C}=4.46$ ). Results suggest that students in the 
TABLE II

Items Measuring Social ENGagement

\begin{tabular}{|c|c|c|c|c|c|c|c|c|c|c|}
\hline$\%$ & & $\begin{array}{c}\text { SD } \\
1 \\
\end{array}$ & 2 & 3 & $\begin{array}{l}\mathbf{N} \\
\mathbf{4} \\
\end{array}$ & 5 & 6 & $\begin{array}{c}\text { SA } \\
7 \\
\end{array}$ & M & SD \\
\hline \multirow{3}{*}{$\begin{array}{l}\text { I was able to get to } \\
\text { know some students } \\
\text { better during the } \\
\text { exam process. }\end{array}$} & $\mathbf{T}$ & 23.0 & 15.8 & 11.5 & 17.3 & 14.4 & 11.5 & 6.5 & 3.45 & 1.93 \\
\hline & $\mathbf{P}$ & 30.9 & 20.0 & 10.9 & 14.5 & 10.0 & 9.1 & 4.5 & 2.98 & 1.89 \\
\hline & & 12.5 & 4.4 & 10.3 & 16.2 & 22.1 & 19.9 & 14.7 & 4.49 & 1.88 \\
\hline \multirow{4}{*}{\multicolumn{2}{|c|}{$\begin{array}{l}\text { The exam process } \\
\text { was mainly a(n): } \\
\text { [Individual or group } \\
\text { experience] : }\end{array}$}} & I. & & & & & & G. & & \\
\hline & & 47.5 & 10.1 & 5.8 & 14.4 & 7.2 & 11.5 & 3.6 & 2.73 & 2.00 \\
\hline & & 48.2 & 17.3 & 6.4 & 8.2 & 11.8 & 4.5 & 3.6 & 2.46 & 1.84 \\
\hline & & 12.5 & 11.8 & 16.2 & 11.8 & 17.6 & 14.0 & 16.2 & 4.17 & 1.99 \\
\hline \multirow{3}{*}{\multicolumn{2}{|c|}{$\begin{array}{l}\text { The CIS } 675 \text { exam } \\
\text { allowed me to form } \\
\text { a kind of learning } \\
\text { community with } \\
\text { other students. }\end{array}$}} & 18.7 & 18.0 & 11.5 & 21.6 & 10.1 & 10.1 & 10.1 & 3.57 & 1.94 \\
\hline & & 17.3 & 15.5 & 6.4 & 20.0 & 20.0 & 10.0 & 10.9 & 3.84 & 1.96 \\
\hline & & 10.3 & 8.8 & 8.1 & 8.8 & 30.1 & 24.3 & 9.6 & 4.51 & 1.81 \\
\hline \multirow{3}{*}{\multicolumn{2}{|c|}{$\begin{array}{l}\text { My understanding of } \\
\text { course material was } \\
\text { enhanced by } \\
\text { interacting with } \\
\text { other students in the } \\
\text { class through the } \\
\text { exam process. }\end{array}$}} & 19.4 & 11.5 & 11.5 & 16.5 & 17.3 & 15.8 & 7.9 & 3.80 & 1.96 \\
\hline & & 18.2 & 13.6 & 10.9 & 16.4 & 16.4 & 16.4 & 8.2 & 3.81 & 1.96 \\
\hline & & 10.3 & 13.2 & 8.1 & 8.8 & 23.5 & 19.9 & 16.2 & 4.46 & 1.96 \\
\hline
\end{tabular}

Note: The course number "CIS675" is shown as an example and it is customized for each course.

T: Traditional Exam; P: Participatory Exam; C: Collaborative Exam SD: Strongly Disagree; N: Neutral; SA: Strongly Agree

I: Individual Experience; G: Group Experience

collaborative exam had the highest adoption of social engagement in exam study. Interestingly, it is also noticeable that the level of social engagement in the participatory exam was lower than or as low as that in the traditional exam on most items. This suggests that without the small group activities, the level of social engagement in the online environment is as low as or even lower than that in the traditional settings.

Student Perceived Learning: Table III provides the results for the 12 items of the perceived-learning construct. In ten out of the 12 items, students in the collaborative exam reported the highest level of learning among the three. For the other two items, the perceptions of students in the participatory exam were the highest. For example, students in the collaborative exam reported the highest level of improvement in their knowledge of the course concepts, methods, and theories ( $\mathrm{T}=4.75, \mathrm{P}=5.18$, and $\mathrm{C}=5.24)$, and their understanding of the course materials $(\mathrm{T}=4.77, \mathrm{P}=4.79$, and $\mathrm{C}=4.89)$. They also reported enhancement in skills such as using knowledge in new situations $(\mathrm{T}=4.71, \mathrm{P}=4.91$, and $\mathrm{C}=4.97)$, solving problems $(\mathrm{T}=4.57, \mathrm{P}=4.84$, and $\mathrm{C}=4.90)$, recognizing patterns $(\mathrm{T}=4.09, \mathrm{P}=4.03$, and $\mathrm{C}=4.13)$, making generalizations and predictions $(\mathrm{T}=4.51, \mathrm{P}=4.66$, and $\mathrm{C}=4.86)$, comparing and discriminating ideas $(\mathrm{T}=4.42, \mathrm{P}=4.56$, and $\mathrm{C}=4.68$ ), and making judgment and assessment of the quality of ideas and arguments $(\mathrm{T}=4.46, \mathrm{P}=4.78$, and $\mathrm{C}=4.91)$. In addition, students in the collaborative exam reported the highest
TABLE III

ItEMs MeAsuring Perceived LeARning

\begin{tabular}{|c|c|c|c|c|c|c|c|c|c|c|}
\hline$\%$ & & $\begin{array}{c}\text { SD } \\
1\end{array}$ & 2 & 3 & $\begin{array}{c}N \\
4\end{array}$ & 5 & 6 & $\begin{array}{c}\text { SA } \\
7\end{array}$ & $\mathbf{M}$ & \\
\hline \multirow{3}{*}{$\begin{array}{l}\text { My ability to judge } \\
\text { the value of ideas } \\
\text { and assess the } \\
\text { quality of arguments } \\
\text { has been improved } \\
\text { through the CIS675 } \\
\text { exam. }\end{array}$} & $\mathbf{T}$ & 4.3 & 9.4 & 6.5 & 28.3 & 28.3 & 313.8 & 9.4 & 4.46 & 1.5 \\
\hline & $\mathbf{P}$ & 1.8 & 5.5 & 5.5 & 22.0 & 35.8 & 823.9 & 5.5 & 4.78 & 1.29 \\
\hline & d & 4.5 & 3.8 & 7.5 & 10.5 & 36.8 & 827.8 & 9.0 & 4.91 & 1.4 \\
\hline \multirow{3}{*}{$\begin{array}{l}\text { My ability to use } \\
\text { methods, concepts, } \\
\text { and theories I } \\
\text { learned in CIS } 675 \\
\text { in new situations } \\
\text { has been improved } \\
\text { through the exam. }\end{array}$} & $\mathbf{T}$ & 4.3 & 5.8 & 10.1 & 15.9 & 31.2 & 23.2 & 9.4 & 4.71 & 1.5 \\
\hline & $\mathbf{P}$ & 3.7 & 4.6 & 7.3 & 17.4 & 27.5 & 527.5 & 11.9 & 4.91 & 1.49 \\
\hline & d & 3.8 & 5.3 & 5.3 & 12.8 & 37.6 & $6 \mid 19.5$ & 15.8 & 4.97 & 1.5 \\
\hline \multirow{3}{*}{$\begin{array}{l}\text { My skill to compare } \\
\text { and discriminate } \\
\text { between ideas has } \\
\text { been improved } \\
\text { through the CIS675 } \\
\text { exam. }\end{array}$} & $\mathbf{T}$ & 5.1 & 6.5 & 10.1 & 29.0 & 28.3 & \begin{tabular}{l|l|l|}
3 & 10.9 \\
\end{tabular} & 10.1 & 4.42 & 1.51 \\
\hline & $\mathrm{P}$ & 1.8 & 7.3 & 8.3 & 28.4 & 30.3 & 317.4 & 6.4 & 4.56 & 1.35 \\
\hline & C & 5.3 & 2.3 & 11.3 & 16.5 & 37.6 & 618.8 & 8.3 & 4.68 & 1.4 \\
\hline \multirow{3}{*}{\multicolumn{2}{|c|}{\begin{tabular}{l|} 
My ability to use \\
course material to \\
make
\end{tabular}}} & 4.3 & 7.2 & 8.7 & 24.6 & 30.4 & 417.4 & 7.2 & 4.51 & 1.48 \\
\hline & & 0.9 & 5.5 & 9.2 & 30.3 & 27.5 & 518.3 & 8.3 & 4.66 & 1.31 \\
\hline & & 5.3 & 3.0 & 5.3 & 22.6 & 27.8 & 822.6 & 13.5 & 4.86 & 1.52 \\
\hline \multirow{3}{*}{$\begin{array}{l}\text { I learned from } \\
\text { answering the exam } \\
\text { questions. }\end{array}$} & $\mathbf{T}$ & 5.1 & 9.4 & 6.5 & 17.4 & 29.7 & 721.0 & 10.9 & 4.64 & 1.6 \\
\hline & $P$ & 0.9 & 4.6 & .9 & 9.2 & 39.4 & 424.8 & 20.2 & 5.37 & 1.2 \\
\hline & d & 3.8 & 2.3 & 3.0 & 5.3 & 30.8 & 832.3 & 22.6 & 5.44 & 1.42 \\
\hline \multirow{3}{*}{\multicolumn{2}{|c|}{$\begin{array}{l}\text { My understanding } \\
\text { of the meaning of } \\
\text { CIS675 course } \\
\text { material has } \\
\text { enhanced through } \\
\text { the exam. }\end{array}$}} & 5.8 & 4.3 & 7.2 & 16.7 & 31.9 & $9 \mid 23.9$ & 10.1 & 4.77 & 1.5 \\
\hline & & 4.6 & 5.5 & 9.2 & 15.6 & 25.7 & 731.2 & 8.3 & 4.79 & 1.5 \\
\hline & & 6.0 & 5.3 & 4.5 & 9.0 & 38.3 & 326.3 & 10.5 & 4.89 & 1.5 \\
\hline \multirow{3}{*}{$\begin{array}{l}\text { I am better able to } \\
\text { see different course } \\
\text { components of } \\
\text { CIS675 and } \\
\text { organize them in a } \\
\text { meaningful way } \\
\text { through the exam. }\end{array}$} & & 8.0 & 8.0 & 11.6 & 30.4 & 19.6 & 617.4 & 5.1 & 4.18 & 1.58 \\
\hline & & 2.8 & 8.3 & 10.1 & 26.6 & 26.6 & $6 \mid 13.8$ & 11.9 & 4.55 & 1.5 \\
\hline & & 4.5 & 4.5 & 13.5 & 22.6 & 30.8 & 816.5 & 7.5 & 4.50 & 1.4 \\
\hline \multirow{3}{*}{\multicolumn{2}{|c|}{$\begin{array}{l}\text { My skill to relate } \\
\text { knowledge from } \\
\text { several areas to } \\
\text { make my argument } \\
\text { has been improved } \\
\text { through the CIS675 } \\
\text { exam. }\end{array}$}} & 3.6 & 6.5 & 8.0 & 26.8 & 31.2 & \begin{tabular}{l|l|}
2 & 13.8 \\
\end{tabular} & 10.1 & 4.57 & 1.4 \\
\hline & & 2.8 & 5.5 & 7.3 & 16.5 & 33.0 & 026.6 & 8.3 & 4.84 & 1.4 \\
\hline & & 6.8 & 2.3 & 9.8 & 14.3 & 34.6 & 621.1 & 11.3 & 4.76 & 1.5 \\
\hline \multirow{3}{*}{\multicolumn{2}{|c|}{\begin{tabular}{l|} 
My ability to \\
recognize patterns \\
of CIS675 course \\
material and their \\
underlying \\
meanings has \\
remained the same \\
as before exam.
\end{tabular}}} & 7.2 & 8.0 & 19.6 & 21.7 & 25.4 & 413.8 & 4.3 & 4.09 & 1.5 \\
\hline & & 3.7 & 12.8 & 21.1 & 23.9 & 22.0 & 011.0 & 5.5 & 4.03 & 1.49 \\
\hline & & 6.0 & 11.3 & 15.8 & 24.1 & 23.3 & 312.8 & 6.8 & 4.13 & 1.58 \\
\hline
\end{tabular}


TABLE III

(Continued.) Items MEASURING PERCEIVEd LEARNING

\begin{tabular}{|c|c|c|c|c|c|c|c|c|c|c|}
\hline$\%$ & & $\begin{array}{c}\text { SD } \\
1\end{array}$ & 2 & 3 & $\begin{array}{l}N \\
4\end{array}$ & 5 & 6 & $\begin{array}{c}\text { SA } \\
7\end{array}$ & M & SD \\
\hline \multirow{3}{*}{$\begin{array}{l}\text { My ability to solve } \\
\text { problems using } \\
\text { what I learned in } \\
\text { CIS675 has NOT } \\
\text { been improved } \\
\text { through the exam. }\end{array}$} & $\mathbf{T}$ & 5.1 & 8.0 & 15.9 & 18.8 & 18.1 & 16.7 & 17.4 & 4.57 & 1.75 \\
\hline & $\mathbf{P}$ & 3.7 & 7.3 & 8.3 & 14.7 & 27.5 & 24.8 & 13.8 & 4.84 & 1.59 \\
\hline & C & 6.0 & 5.3 & 7.5 & 14.3 & 25.6 & 23.3 & 18.0 & 4.90 & 1.69 \\
\hline \multirow{3}{*}{$\begin{array}{l}\text { I learned from } \\
\text { reading the exam } \\
\text { questions posted } \\
\text { online. }\end{array}$} & $\mathbf{T}$ & 10.9 & 9.4 & 5.8 & 24.6 & 16.7 & 18.8 & 13.8 & 4.38 & 1.86 \\
\hline & $\mathbf{P}$ & 2.8 & 11.9 & 5.5 & 19.3 & 29.4 & 21.1 & 10.1 & 4.64 & 1.56 \\
\hline & $\mathrm{C}$ & 3.8 & 3.0 & 11.3 & 19.5 & 30.1 & 21.8 & 10.5 & 4.77 & 1.46 \\
\hline \multirow{3}{*}{$\begin{array}{l}\text { My knowledge of } \\
\text { major concepts, } \\
\text { methods, and } \\
\text { theories of CIS } 675 \\
\text { has NOT been } \\
\text { improved through } \\
\text { the exam. } \mathbf{R}\end{array}$} & $\mathbf{T}$ & 6.5 & 8.7 & 10.1 & 13.0 & 21.7 & 18.8 & 21.0 & 4.75 & 1.83 \\
\hline & $\mathbf{P}$ & 3.7 & 5.5 & 10.1 & 9.2 & 19.3 & 25.7 & 26.6 & 5.18 & 1.70 \\
\hline & C & 5.3 & 5.3 & 9.8 & 4.5 & 17.3 & 30.8 & 27.1 & 5.24 & 1.76 \\
\hline
\end{tabular}

level of learning in reading exam questions posted online $(\mathrm{T}=4.38, \mathrm{P}=4.64$, and $\mathrm{C}=4.77)$ and in answering exam questions $(\mathrm{T}=4.64, \mathrm{P}=5.37$, and $\mathrm{C}=5.44)$. Students in the participatory exam reported the highest level of improvement in seeing different course components and organizing them in a meaningful way $(\mathrm{T}=4.18, \mathrm{P}=4.55$, and $\mathrm{C}=4.50)$, and relating knowledge from different academic areas $(\mathrm{T}=4.57$, $\mathrm{P}=4.84$, and $\mathrm{C}=4.76$ ). In 11 out of the 12 items, students in the traditional exam reported the lowest level of perceived learning among the three exams.

Student Satisfaction: Table IV presents the results of the four items included in the satisfaction construct. In terms of time frame, students in the traditional exam had the highest perception of the exam being conducted in a comfortable time frame $(\mathrm{T}=5.28, \mathrm{P}=4.47$, and $\mathrm{C}=4.81)$. This corresponds to the students' answers to the open-ended questions, where the two-week time frame of the online exam was reported as too long compared with the couple of hours typically spent in a traditional exam. Students in the online exams had slightly lower levels of pressure compared with the traditional exam (reversed score: $\mathrm{T}=4.27, \mathrm{P}=4.32$, and $\mathrm{C}=4.41$ ), and they reported more enjoyment with the exam process $(\mathrm{T}=4.09, \mathrm{P}=4.37$, and $\mathrm{C}=4.43$ ). There was no noticeable difference in terms of the preference of recommending the exam process to be used in the future ( $\mathrm{T}=4.64, \mathrm{P}=4.68$, and $\mathrm{C}=4.64)$. Students commented in the open-ended questions that although they enjoyed the easy access to resources and less pressure with the online exams, the lengthy exam timeline and the multiple deadlines were some main issues they had to overcome, which affected their recommendation for the process to be used in the future.

\section{Hypothesis Testing}

To test the hypotheses, the mean scores were calculated for all the factors, and the transformed mean score (mean square) was used for perceived learning in the following tests. To
TABLE IV

ITEMS MEASURING SATISFACTION

\begin{tabular}{l|c|c|c|c|c|c|c|c|c|c}
\hline \multicolumn{1}{c}{$\%$} & & $\mathbf{S D}$ & & & $\mathbf{N}$ & & & $\mathbf{S A}$ & $\mathbf{M}$ & $\mathbf{S D}$ \\
\hline \multirow{3}{*}{$\begin{array}{l}\text { The exam provided a } \\
\text { comfortable } \\
\text { timeframe. }\end{array}$} & $\mathbf{T}$ & 3.6 & 2.9 & 7.2 & 10.9 & 20.3 & 33.3 & 21.7 & 5.28 & 1.54 \\
\cline { 2 - 10 } & $\mathbf{P}$ & 9.2 & 9.2 & 14.7 & 11.0 & 19.3 & 22.0 & 14.7 & 4.47 & 1.88 \\
\cline { 2 - 10 } & $\mathbf{C}$ & 10.5 & 6.8 & 9.8 & 6.8 & 19.5 & 23.3 & 23.3 & 4.81 & 1.98 \\
\hline $\begin{array}{l}\text { I felt under a lot of } \\
\text { pressure taking the } \\
\text { exam this way. }\end{array}$ & $\mathbf{T}$ & 6.5 & 13.0 & 21.7 & 10.9 & 15.2 & 18.8 & 13.8 & 4.27 & 1.85 \\
\cline { 2 - 10 } & $\mathbf{P}$ & 9.2 & 12.8 & 18.3 & 9.2 & 11.9 & 23.9 & 14.7 & 4.32 & 1.96 \\
\hline \multirow{3}{*}{$\begin{array}{l}\text { I enjoyed the } \\
\text { examination process }\end{array}$} & $\mathbf{C}$ & 10.5 & 9.8 & 14.3 & 14.3 & 15.8 & 15.0 & 20.3 & 4.41 & 1.98 \\
\cline { 2 - 10 } & $\mathbf{T}$ & 10.9 & 12.3 & 10.1 & 24.6 & 18.8 & 11.6 & 11.6 & 4.09 & 1.81 \\
\hline
\end{tabular}

TABLE V

OVERALL COMPARISON-ANOVA TEST

\begin{tabular}{|c|c|c|c|c|c|c|}
\hline $\begin{array}{l}\text { Exam Study } \\
\text { Strategies \& } \\
\text { Outcomes }\end{array}$ & Exam Mode & $\mathbf{N}$ & Mean & S. D. & $\mathbf{F}$ & Sig \\
\hline \multirow{3}{*}{$\begin{array}{l}\text { Social } \\
\text { Engagement }\end{array}$} & Traditional & 139 & 3.38 & 1.6 & \multirow{3}{*}{$22.5 * *$} & \multirow{3}{*}{.00} \\
\hline & Participatory & 110 & 3.27 & 1.5 & & \\
\hline & Collaborative & 136 & 4.41 & 1.4 & & \\
\hline \multirow{3}{*}{$\begin{array}{l}\text { Perceived } \\
\text { Learning }^{\mathrm{T}}\end{array}$} & Traditional & 138 & 21.78 & 10.3 & \multirow{3}{*}{$3.1^{*}$} & \multirow{3}{*}{.05} \\
\hline & Participatory & 109 & 23.91 & 10.0 & & \\
\hline & Collaborative & 133 & 24.78 & 10.2 & & \\
\hline \multirow{3}{*}{ Satisfaction } & Traditional & 138 & 4.57 & 1.3 & \multirow{3}{*}{.22} & \multirow{3}{*}{.80} \\
\hline & Participatory & 109 & 4.46 & 1.6 & & \\
\hline & Collaborative & 133 & 4.57 & 1.6 & & \\
\hline
\end{tabular}

compare the differences among the three exam modes and to test the hypothesis, a one-way analysis of variance (ANOVA) test was conducted. Table V shows the results.

Significant differences in social engagement $(p<.01)$ and perceived learning $(p<.05)$ were found among the three exam modes. Post hoc analysis reveals that in terms of social engagement, students in the collaborative exam were significantly more engaged than students in the traditional $(p<.01)$ and the participatory exams $(p<.01)$. In terms of perceived learning, students in the collaborative exam reported significantly higher perceptions of learning than those in the traditional exam $(p<.05)$. Therefore, under H1.1, both H1.1.1 and H1.1.2 are supported. Under H1.2, H1.2.1 is supported. H1.3 is not supported. 
TABLE VI

PERCEIVEd LEARNING AND SOCIAL ENGAgEMENT IN TRAditionaL AND COLLABORATIVE EXAMS (CORRELATION)

\begin{tabular}{|c|c|c|}
\hline & & $\begin{array}{l}\text { Perceived } \\
\text { Learning }^{\mathrm{T}}\end{array}$ \\
\hline \multirow{2}{*}{$\begin{array}{l}\text { Social } \\
\text { Engagement }\end{array}$} & Traditional & $.369 * *$ \\
\hline & Collaborative & $.574 * *$ \\
\hline
\end{tabular}

TABLE VII

SATISFACTION AND SOCIAL ENGAGEMENT IN TRADITIONAL AND COLlaborative EXAMS (CORRELATION)

\begin{tabular}{|l|l|r|}
\cline { 3 - 3 } \multicolumn{2}{c|}{} & Social \\
Engagement & Traditional & $.237^{* *}$ \\
\cline { 2 - 3 } & Collaborative & $.496^{* *}$ \\
\hline
\end{tabular}

To test hypothesis two, correlation analysis using Pearson's $r$ was conducted for perceived learning and satisfaction. The result shows that the two constructs are significantly correlated at the $r=.617$ level. Therefore, $\mathrm{H} 2$ is supported $(r=.617$, $p<.01)$.

The mediating effect of social engagement on students' perceptions of the exam was explored via the differences in the correlation between perceived learning and social engagement in the traditional and the collaborative exam modes. To do so, the correlation between perceived learning and social engagement was calculated for the two exam modes, respectively. As the results show in Table VI, the correlation is higher in the collaborative exam than in the traditional exam. Therefore, H3. 1 is supported.

Similarly, to explore the differences in the correlation between satisfaction and social engagement in the traditional and the collaborative exam modes, the correlation between satisfaction and social engagement was calculated for the two exam modes, respectively. As the results show in Table VII, the correlation is higher in the collaborative exam than in the traditional exam. Therefore, H3.2 is supported.

The results are summarized in Fig. 5, which is the research model in Fig. 1 but with results. The numbers beside the lines are correlation coefficient Pearson's $r$. Significant differences found among the exam modes are highlighted with bold box outlines.

\section{Conclusion}

A literature review suggests that interaction and higher order learning are keys to effective online learning [31]. Regarding interaction, this paper has shown that incorporating small group activities into the online learning process can significantly increase interaction among students and enhance their sense of an online learning community. Significant differences in the level of social engagement, which is defined as the extent of students' active involvement in learning from other students in

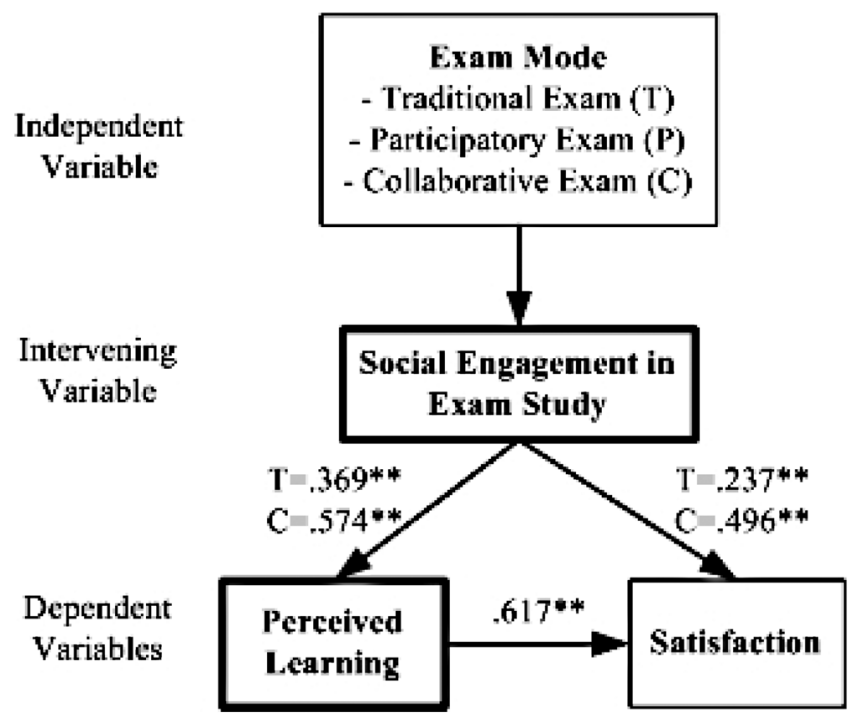

Fig. 5. Research framework with results.

exam studying, and the sense of forming a learning community were found between the collaborative exam and the two other exam modes. Results show that the collaborative online exam, which incorporated small group activities, resulted in significantly higher levels of interaction among students, which enhanced their understanding of course materials. Students got to know other students better through the exam process, perceived the exam as a group process, and formed a sense of a learning community. In contrast, the participatory online exam, which did not incorporate small group activities, resulted in the same low level of social engagement as that in the traditional exam. This finding indicates that without incorporating small group activities into the online learning process, the level of interaction and the sense of a learning community are as low as those in traditional exam processes.

Regarding higher order learning, this paper demonstrates that significant differences exist between the collaborative exam and the traditional exam regarding perceived learning, based on Bloom's taxonomy, which measures learning from lower levels such as understanding the materials to higher levels such as solving problems and making generalizations. This paper shows that through active involvement and small group activity (creating questions, peer assessment, intense discussion, and coordinated activities), students in the collaborative exam reported significantly higher perceptions of learning than students in the traditional exam, including enhancement of skills in using knowledge in new situations, solving problems, recognizing patterns, making generalizations and predictions, and making judgments, and assessing the quality of arguments. Thus, the results indicate that the use of collaborative examination processes in online courses can significantly improve student learning.

While this paper reported an increase in perceived learning, future research should add measures of "objective" learning to the measures of subjective learning in order to further validate this conclusion. Another area that requires further exploration is the long-term effect of the collaborative examination on 
students' learning and interaction online. While the effect of the collaborative exam was measured only once after the exam in this paper, there were some indications that the exam may have long-term effects. For example, students who took the online exam more than once reported more familiarity with the exam process and enjoyed the exam process more. In addition, other factors that may have confounded the results such as length of exams need to be further examined. Given that the online exams in this paper take about two weeks to complete, the issue of streamlining the process to further improve its efficiency needs to be studied. Further studies should be conducted to investigate these issues in collaborative examinations and collaborative learning, which are prominent in investigating learning and knowledge sharing in an online environment.

\section{ACKNOWLEDGMENT}

The authors would like to thank I. Im, K. Passerini, J. Scher, and D. Leidner for their valuable input and support to this research, as well as all the faculty members and students who participated in the experiments of this paper. The opinions suggested are those of the authors and not necessarily those of the sponsors of this research.

\section{REFERENCES}

[1] S. R. Hiltz, The Virtual Classroom: Learning Without Limits via Computer Networks. Norwood, NJ: Ablex, 1994.

[2] W. E. Deming, Out of the Crisis. Cambridge, MA: MIT Press, 1986.

[3] L. Olson, "Quality-management movement spurs interest in new awards for education," Educ. Week, vol. 11, no. 26, p. 8, 1992.

[4] B. D. Wright, "More art than science: The post-secondary assessment movement today," in Elements of Quality Online Education: Into the Mainstream, ser. Sloan-C, vol. 5, J. Bourne and J. Moore, Eds. Needham, MA: Sloan Center for Online Education, 2003, pp. 185-198.

[5] D. E. Leidner and S. L. Jarvenpaa, "The use of information technology to enhance management school education: A theoretical view," MIS Q., vol. 19, no. 3, pp. 265-291, 1995.

[6] J. Piaget, Science of Education and the Psychology of the Child. New York: Grossman, 1970.

[7] — The Mechanisms of Perception. London, U.K.: Rutledge and Kegan Paul, 1969.

[8] M. E. Huba and J. E. Freed, Learner-Centered Assessment on College Campuses: Shifting the Focus From Teaching to Learning, 1st ed. Boston, MA: Allyn and Bacon, 1999.

[9] T. A. Angelo and K. P. Cross, Classroom Assessment Techniques: A Handbook for College Teachers, 2nd ed. San Francisco, CA: JosseyBass, 1993.

[10] L. Vygotsky, Thought and Language. Cambridge, MA: MIT Press, 1962.

[11] M. Alavi, "Computer-mediated collaborative learning: An empirical evaluation," MIS Q., vol. 18, no. 2, pp. 159-174, Jun. 1994.

[12] S. R. Hiltz, "Productivity enhancement from computer-mediated communication: A system contingency approach," Сотmun. ACM, vol. 31, no. 12 , pp. 1438-1454, Dec. 1988.

[13] S. J. Sloffer, B. Dueber, and T. M. Duffy, "Using asynchronous conferencing to promote critical thinking: Two implementations in higher education," in Proc. 32nd Hawaii Int. Conf. Syst. Sci., 1999, p. 1083.

[14] E. Wenger, Communities of Practice: Learning, Meaning, and Identity. Cambridge, U.K.: Cambridge Univ. Press, 1998.

[15] R. C. W. Kwok and J. Ma, "Use of a group support system for collaborative assessment," Comput. Educ., vol. 32, no. 2, pp. 109-125, Feb. 1999.

[16] E. V. Wilson, "Examnet asynchronous learning network: Augmenting face-to-face course with student-developed exam questions," Comput. Educ., vol. 42, no. 1, pp. 87-107, Jan. 2004.

[17] J. Shindler, "Greater than the sum of the parts? Examining the soundness of collaborative exams in teacher education courses," Innov. High. Educ., vol. 28, no. 4, p. 273, Jun. 1, 2004.
[18] N. Falchikov and J. Goldfinch, "Student peer assessment in higher education: A meta-analysis comparing peer and teacher marks," Rev. Educ. Res., vol. 70, no. 3, pp. 287-322, 2000.

[19] K. J. Topping, "Peer assessment between students in college and university," Rev. Educ. Res., vol. 68, no. 3, pp. 249-276, 1998.

[20] D. M. A. Sluijsmans, S. Brand-Gruwel, J. Van Merriënboer, and T. R. Bastiaens, "The training of peer assessment skills to promote the development of reflection skills in teacher education," Stud. Educ. Eval. vol. 29, no. 1, pp. 23-42, 2003

[21] J. Shen, M. Bieber, and S. R. Hiltz, "Participatory examinations in asynchronous learning networks: Longitudinal evaluation results," J. Asynchr. Learn. Netw., vol. 9, no. 3, pp. 93-113, 2005.

[22] J. Shen, K.-E. Cheng, M. Bieber, and S. R. Hiltz. (2004). "Traditional inclass examination vs. collaborative online examination in asynchronous learning networks: Field evaluation results," Proc. Amer. Conf. Inf. Syst., New York. [Online]. Available: http://plone.aisnet.org/

[23] J. Shen, S. R. Hiltz, K.-E. Cheng, Y. Cho, and M. Bieber, "Collaborative examinations for asynchronous learning networks: Evaluation results," in Proc. 34th Hawaii Int. Conf. Syst. Sci., Maui, HI, 2001, p. 1006.

[24] D. Wu, M. Bieber, S. R. Hiltz, and H. Han, "Constructivist learning with participatory examinations," in Proc. 37th HICSS, Big Island, HI, 2004, p. 10004.1.

[25] R. Benbunan-Fich, S. R. Hiltz, and L. Harasim, "The online interaction learning model: An integrated theoretical framework for learning networks," in Learning Together Online: Research on Asynchronous Learning Networks, S. R. Hiltz and R. Goldman, Eds. Mahwah, NJ: Lawrence Erlbaum, 2005.

[26] B. Bloom, A Taxonomy of Educational Objectives: The Classification of Educational Goals. New York: D. McKay Co., 1956.

[27] J. Biggs, D. Kember, and D. Y. P. Leung, "The revised two-factor study process questionnaire: R-Spq-2f," Br. J. Educ. Psychol., vol. 71, no. 1, pp. 133-149, Mar. 2001.

[28] C. Tang. (1994). "Effects of modes of assessment on students' preparation strategies," in Improving Student Learning-Theory and Practice, G. Gibbs, Ed. Oxford: Oxford Centre for Staff Development. [Online]: Available: http://www.city.londonmet.ac.uk/deliberations/ocsdpubs/isltp-tang.html

[29] M. Alavi and D. Dufner, "Technology-mediated collaborative learning: A research perspective," in Learning Together Online: Research on Asynchronous Learning Networks, S. R. Hiltz and R. Goldman, Eds. Mahwah, NJ: Lawrence Erlbaum, 2005.

[30] D. Leidner and M. Fuller, "Improving student learning of conceptual information: GSS supported collaborative learning vs. individual constructive learning," Decis. Support Syst., vol. 20, no. 2, pp. 149-163, Jun. 1997.

[31] G. Lorenzo and J. Moore. (2002). "Five pillars of quality online education," in Proc. Sloan Consort. Rep. Nation. [Online]. Available: http://www.aln.org/effective/pillarreport1.pdf

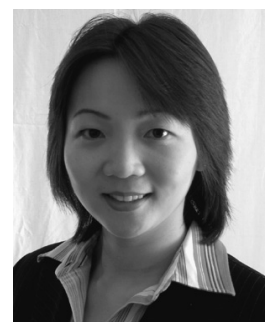

Jia Shen received the B.S. degree in computer science and engineering from the Beijing University of Technology, Beijing, China, the M.S. degree in information systems from the New Jersey Institute of Technology (NJIT), Newark, and the Ph.D. degree in information systems from NJIT, in 2005.

She is currently an Assistant Professor of management information systems with the School of Management, New York Institute of Technology, New York. Her research interest is the human factors of information systems, including online learning, virtual teamwork, human-computer interaction, and knowledge management. Prof. Shen is a member of the Association for Information Systems. 


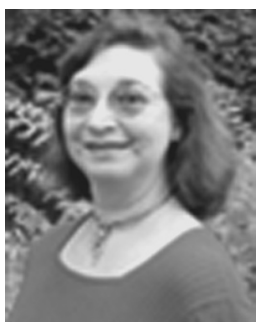

Starr Roxanne Hiltz received the Ph.D. degree in sociology from the University of Columbia, New York, in 1969.

She is a Distinguished Professor with the College of Computing Sciences, New Jersey Institute of Technology, Newark. A sociologist by training, she has been working on the applications and social impacts of computer technology for the past 30 years. She has also published in journals including the Journal of Management Information Systems, Communications of the ACM, and IEEE Transactions. Her most recent book, which she coedited with R. Goldman, is entitled Learning Together Online: Research on Asynchronous Learning Networks (Lawrence Erlbaum, 2005). Her current research interests include group support systems, asynchronous learning networks, and pervasive computing.

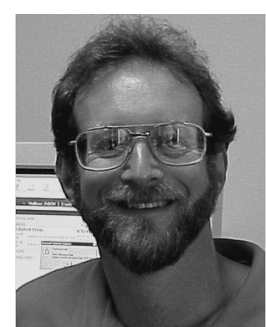

Michael Bieber received the Ph.D. degree in decision sciences from the University of Pennsylvania, Philadelphia, in 1990

$\mathrm{He}$ is currently a Professor with the Department of Information Systems, College of Computing Sciences, New Jersey Institute of Technology, Newark, where he conducts research in several related areas, such as participatory learning, hypermedia functionality, automatically generating links and services for Web applications and digital libraries, relationship analysis (as part of the software engineering process), and virtual communities.

Prof. Bieber is a member of the Association of Information Systems and the Association for Computing Machinery Special Interest Group on Hypertext, Hypermedia, and the Web. 